\title{
Vesicular Sterols Are Essential for Synaptic Vesicle Cycling
}

\author{
Jeffrey S. Dason, Alex J. Smith, Leo Marin, and Milton P. Charlton \\ Department of Physiology, University of Toronto, Toronto, Ontario M5S 1A8, Canada
}

Synaptic vesicles have a high sterol content, but the importance of vesicular sterols during vesicle recycling is unclear. We used the Drosophila temperature-sensitive dynamin mutant, shibire-tsl, to block endocytosis of recycling synaptic vesicles and to trap them reversibly at the plasma membrane where they were accessible to sterol extraction. Depletion of sterols from trapped vesicles prevented recovery of synaptic transmission after removal of the endocytic block. Measurement of vesicle recycling with synaptopHluorin, FM1-43, and FM4-64 demonstrated impaired membrane retrieval after vesicular sterol depletion. When plasma membrane sterols were extracted before vesicle trapping, no vesicle recycling defects were observed. Ultrastructural analysis indicated accumulation of endosomes and a defect in the formation of synaptic vesicles in synaptic terminals subjected to vesicular sterol depletion. Our results demonstrate the importance of a high vesicular sterol concentration for endocytosis and suggest that vesicular and membrane sterol pools do not readily intermingle during vesicle recycling.

\section{Introduction}

Sustained synaptic transmission requires endocytosis and recycling of synaptic vesicles to replenish the releasable vesicle pool (for review, see $\mathrm{Wu}$ et al., 2007). Sterols are required in nonneuronal cells for constitutive and receptor-mediated clathrindependent endocytosis (Rodal et al., 1999; Subtil et al., 1999; Urs et al., 2005). Synaptic vesicles have a high sterol content (Takamori et al., 2006), but the role of sterols in synaptic vesicle endocytosis is not well understood. Extraction of sterols with methyl$\beta$-cyclodextrin $(\mathrm{M} \beta \mathrm{CD})$ does not affect FM1-43 loading and unloading in cultured cortical and hippocampal neurons (Suzuki et al., 2004); however, the uptake of HRP by synaptic vesicles during high $\mathrm{K}^{+}$stimulation and the total number of vesicles in synaptic terminals is reduced after $\mathrm{M} \beta \mathrm{CD}$ treatment (Wasser et al., 2007). One potential explanation for this apparent discrepancy is that recycling vesicles rely on vesicle-derived sterols, not on a plasma membrane-derived sterol pool, during endocytosis.

Sterols are required for the spatial segregation of protein contents of synaptic vesicle and plasma membranes into lipid raft domains (Thiele et al., 2000; Lang et al., 2001; Mitter et al., 2003; Yoshinaka et al., 2004; Jia et al., 2006; Lv et al., 2008). It is unclear whether these domains remain distinct during synaptic vesicle recycling, and, more generally, the degree of dispersal of exocytosed vesicular membrane proteins remains unknown. For instance, exocytosed synaptotagmin remains clustered in vesiclesized patches after release into the plasma membrane (Willig et al., 2006); however, substantial interchange of some synaptic vesicle proteins with a surface resident pool can occur during vesicle

Received Aug. 6, 2010; revised Sept. 21, 2010; accepted Sept. 24, 2010.

This work was supported by Canadian Institutes of Health Research, Canada, Grant MOP-82827 (M.P.C.). We thank Dr. Harold Atwood for critically reading this manuscript, Dr. Graeme Davis and Dr. Bryan Stewart for fly stocks, Yan Chen for technical assistance with electron microscopy, and Marianne Hegström-Wojtowicz for helping maintain fly stocks.

Correspondence should be addressed to Milton P. Charlton at the above address. E-mail: milton.charlton@ utoronto.ca.

DOI:10.1523/JNEUROSCI.4132-10.2010

Copyright $\odot 2010$ the authors $\quad$ 0270-6474/10/3015856-10\$15.00/0 recycling (Fernández-Alfonso et al., 2006; Wienisch and Klingauf, 2006). Vesicle-derived lipophilic dyes disperse into the plasma membrane after fusion (Zenisek et al., 2002), but the extent of mixing between endogenous vesicular and plasma membrane lipids is unknown.

The Drosophila dynamin mutant, shibire-ts1 (shi) undergoes reversible, temperature-sensitive, endocytic blockade and can be used to trap recycling vesicles at the plasma membrane (Koenig and Ikeda, 1989; Ramaswami et al., 1994). Here, we used this mutant to determine whether there are distinct requirements for plasma membrane and vesicle-derived sterols during synaptic vesicle recycling. Depletion of sterols from trapped vesicles with $\mathrm{M} \beta \mathrm{CD}$ severely impaired vesicle endocytosis and blocked synaptic transmission, but both were unaffected if only the plasma membrane was depleted of sterols before exocytosis. These results demonstrate that high vesicular sterol content is required for synaptic vesicle recycling and suggest that there is a limited interchange of sterols between plasma and synaptic vesicle membrane pools.

\section{Materials and Methods}

Fly stocks. All fly stocks were grown in uncrowded conditions at $22^{\circ} \mathrm{C}$ on cornmeal agar with dry yeast (corn meal, $0.09 \mathrm{~g} / \mathrm{ml}$; agar, $0.005 \mathrm{~g} / \mathrm{ml}$; yeast extract, $0.005 \mathrm{~g} / \mathrm{ml}$; corn syrup, $0.11 \mathrm{ml} / \mathrm{ml}$; whole milk powder, $0.02 \mathrm{~g} / \mathrm{ml} ; 99 \%$ propionic acid, $0.002 \mathrm{ml} / \mathrm{ml} ; 85 \%$ phosphoric acid, $0.0002 \mathrm{ml} / \mathrm{ml}$ ). Assuming $100 \mathrm{mg}$ of cholesterol per $100 \mathrm{~g}$ of whole milk powder [http://www.nal.usda.gov/fnic/foodcomp/cgi-bin/list_nut_edit. pl; U.S. Department of Agriculture National Nutrient Database for Standard Reference, Release 22 (2009)], there was $\sim 0.02 \mathrm{mg} / \mathrm{ml}$ or $0.052 \mathrm{~mm}$ cholesterol in the larval growth medium.

Wandering third-instar larvae were used for all experiments. Oregon Red $(O R)$ was used as the wild-type control, since the temperaturesensitive shibire-ts 1 (shi) mutant was generated by EMS (ethyl methanesulfonate) mutagenesis of OR flies (Grigliatti et al., 1973). OR and shi flies were kindly provided by Dr. Bryan Stewart (University of Toronto, Toronto, Ontario, Canada). Flies with the UAS- $n-S y b-p H$ transgene recombined with $e l a V^{3 E 1}$-GAL4 and balanced with a TM6b chromosome (Poskanzer et al., 2003; Poskanzer and Davis, 2004) were a generous gift from Dr. Graeme 
Davis (University of California, San Francisco, San Francisco, CA). For synaptopHluorin imaging experiments, male $+;+; U A S-n-S y b-p H$, elaV $V^{3 E 1}$ GAL4/TM6b flies were crossed to female shi; +;+ flies, and nontubby male larvae (shi;+;UAS-n-Syb-pH,elaV ${ }^{3 E 1}$-GAL4/+) were selected.

Solutions and chemicals. All electrophysiological and imaging experiments were conducted in the hemolymph-like solution HL6 supplemented with $1 \mathrm{~mm} \mathrm{CaCl}_{2}$ (Macleod et al., 2002). The osmolality of all solutions used was $330 \pm 10 \mathrm{mOsm}$. $\mathrm{M} \beta \mathrm{CD}$ and cholesterol were obtained from Sigma-Aldrich. Cholesterol-M $\beta C D$ was prepared by dissolving cholesterol in chloroform and then evaporating under a stream of nitrogen (Churchward et al., 2005). Ten millimolar M $\beta$ CD HL6 was then added to the dried film at a molar ratio of 1:10 (cholesterol-M $\beta C D$ ). Suspensions were bath sonicated for $1 \mathrm{~h}$ and then filtered through $0.2 \mu \mathrm{m}$ filters (Millipore). To determine whether the 1:10 cholesterol-M $\beta C D$ complex is capable of extracting other lipophilic molecules, we measured the fluorescence intensity of 1:10 cholesterol-M $\beta C D$ and $10 \mathrm{mM} \mathrm{M} \beta C D$ solutions containing $10 \mu \mathrm{M}$ FM1-43 in a 96-well plate using a fluorescence scanner (Ettan DIGE Imager; GE Healthcare). The fluorescence intensity of both the $\mathrm{M} \beta \mathrm{CD}[21,345 \pm 606$ arbitrary units (a.u.); $n=3]$ and 1:10 cholesterol-M $\beta \mathrm{CD}(21,962 \pm 343$ a.u.; $n=3)$ solutions containing FM1-43 were similar, indicating that they take up similar amounts of FM1-43. This demonstrates that the 1:10 cholesterol-M $\beta C D$ complex can be used as a control for $\mathrm{M} \beta \mathrm{CD}$, since they both can extract other lipophilic molecules. Thus, any effect observed with $\mathrm{M} \beta \mathrm{CD}$ but not with the 1:10 cholesterol-M $\beta \mathrm{CD}$ would be attributable to the sterolextracting activity of $\mathrm{M} \beta \mathrm{CD}$.

Chobimalt (Anatrace) consists of two maltosyl units linked to cholesterol at the hydrophilic $\mathrm{OH}$. Cholesterol-3-sulfate was obtained from US Biological.

Sterol measurements. Dissected third-instar larval fillet preparations were treated with HL6 or with HL6 plus $10 \mathrm{~mm} \mathrm{M} \beta C D$ for $30 \mathrm{~min}$, and then transferred to Eppendorf tubes containing $200 \mu \mathrm{l}$ of $1 \times$ reaction buffer $\left(100 \mathrm{~mm} \mathrm{~K}_{2} \mathrm{PO}_{4}, 25 \mathrm{~mm} \mathrm{NaCl}, 2.5 \mathrm{~mm}\right.$ cholic acid, and $0.1 \%$ Triton $\mathrm{X}-100, \mathrm{pH} 7.4$ ) and frozen in liquid $\mathrm{N}_{2}$. Fillet preparations were lysed mechanically with a plastic pestle then spun at $1000 \times g$ for 5 min to pellet the cuticle. Fifty microliters of supernatant was used to quantify sterols using the Amplex Red Cholesterol Assay kit (Invitrogen) according to the manufacturer's instructions with the cholesterol esterase step omitted. Resorufin product was imaged in 96-well plates with a CCD-based fluorescent scanner (Ettan DIGE Imager; GE Healthcare) and quantified with ImageJ software. Protein concentration of lysates was measured spectrophotometrically using Bradford Reagent (Sigma-Aldrich) with BSA standards according to the manufacturer's instructions.

Electrophysiology. Intracellular recordings were performed as previously described (Romero-Pozuelo et al., 2007). Briefly, sharp glass electrodes filled with $3 \mathrm{M} \mathrm{KCl}(\sim 40 \mathrm{M} \Omega)$ were used to impale the ventral longitudinal muscle fiber 6 (abdominal segment 3 ) of dissected larvae to measure spontaneously occurring miniature excitatory junction potentials (mEJPs) and stimulus-evoked excitatory junction potentials (EJPs). Cut segmental nerves were stimulated at either 0.05 or $10 \mathrm{~Hz}$ using a suction electrode. Electrical signals were recorded using the MacLab/4S data acquisition system (ADInstruments).

SynaptopHluorin imaging. All synaptopHluorin experiments were performed using a Bio-Rad MRC 600 confocal scan head on a Nikon microscope (Optiphot-2) with a $40 \times$ water dipping objective [ 0.7 numerical aperture (NA)]. The argon laser was attenuated to $1 \%$ transmission using neutral density filters. The pinhole of the photomultiplier tube was opened to its maximum aperture. Fluorescence $(F)$ was reported with background $F$ subtracted. The fluorescence response was reported as the change in fluorescence relative to the resting fluorescence. This change in fluorescence was normalized to the resting fluorescence, using the following equation: $\Delta F / F_{\text {rest }}=\left(F-F_{\text {rest }}\right) / F_{\text {rest }}$.

FM1-43 and FM4-64 imaging. $\beta$-Cyclodextrins can bind styryl dyes and extract them from membranes (Kay et al., 1999). Styryl dyes fluoresce when bound by cyclodextrin; we measured the fluorescence intensity of a dilution series of $\mathrm{M} \beta \mathrm{CD}$ solutions containing $10 \mu \mathrm{M}$ FM1-43 or FM4-64 (supplemental Fig. 3, available at www.jneurosci.org as supplemental material) in a 96-well plate using a fluorescence scanner (Ettan DIGE Imager; GE Healthcare). The intensity data were fit with a one-site binding
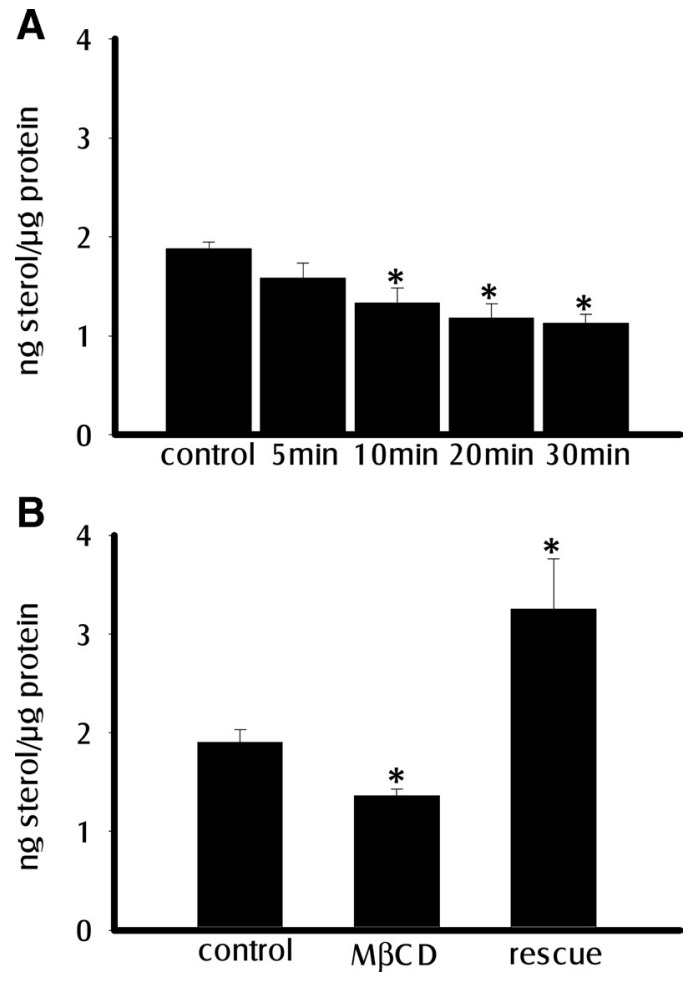

Figure 1. Treatment with $M \beta C D$ reduces sterol levels in larval fillet preparation. $\boldsymbol{A}$, Sterol levels were quantified using the Amplex red sterol assay under control conditions and after treatment with $10 \mathrm{~mm} M \beta C D$ for the indicated time durations. Sterol levels were significantly reduced after 10,20 , or 30 min exposure to $10 \mathrm{~mm} M \beta C D$ compared with controls ( $n=6 ; p<$ 0.01). $\boldsymbol{B}$, After sterol depletion with $10 \mathrm{~mm} M \beta C D$ for $30 \mathrm{~min}$, sterol levels were rescued by the application of 1:10 cholesterol-M $\beta C D$ for $2 \min (n=6 ; p<0.01)$. Error bars represent SEM. *Significantly different from control.

equation of $y=B_{\max } \cdot[X] /\left(K_{\mathrm{d}}+[X]\right)$ to give apparent dissociation coefficients of $65 \mu \mathrm{M}$ for FM1-43 and $50 \mu \mathrm{M}$ for FM4-64. Since M $\beta$ CD binds styryl dyes, we judged that dye uptake could not be used to assess endocytosis when the styryl dye and $\mathrm{M} \beta \mathrm{CD}$ were present simultaneously; these compounds were therefore applied sequentially in our dye-loading protocol.

All FM1-43 and FM4-64 experiments were performed using a Leica TCS LS confocal laser-scanning microscope with a $40 \times$ water dipping objective (0.8 NA). FM1-43 or FM4-64 loading and unloading were induced by high $\mathrm{K}^{+}$depolarization using the following high $\mathrm{K}^{+}$saline: 25 mм NaCl, 90 mм KCl, $10 \mathrm{~mm} \mathrm{NaHCO}_{3}, 5$ mм HEPES, 30 mм sucrose, 5 mM trehalose, $10 \mathrm{~mm} \mathrm{MgCl}_{2}, 2 \mathrm{~mm} \mathrm{CaCl}_{2}, \mathrm{pH} 7.2$ (Verstreken et al., 2008). shi preparations were depleted of synaptic vesicles by high $\mathrm{K}^{+}$ saline at $30^{\circ} \mathrm{C}$ and then loaded with $10 \mu \mathrm{M}$ FM1-43 or FM4-64 (Invitrogen) at $22^{\circ} \mathrm{C}$. Preparations were extensively washed for $10 \mathrm{~min}$ in calcium free HL6. To reduce background fluorescence from extracellular FM1-43 or FM4-64, $75 \mu \mathrm{M}$ Advasep-7 was included for the first $2 \mathrm{~min}$ of the wash (Kay et al., 1999). After an image of FM1-43 or FM4-64 uptake was taken, high $\mathrm{K}^{+}$depolarization for $10 \mathrm{~min}$ was used to induce exocytosis. Another image was then taken to document FM1-43 or FM4-64 unloading.

Electron microscopy. EJPs were recorded from stimulated preparations to verify depletion or recovery. Specimens were processed as previously described (Macleod et al., 2004). Briefly, specimens were fixed in $0.1 \mathrm{M}$ sodium cacodylate buffer containing $1 \%$ formaldehyde and $3 \%$ glutaraldehyde, $\mathrm{pH} 7.4$, overnight and then trimmed to allow identification of the stimulated segment. Depleted preparations were immediately fixed in preheated $\left(30^{\circ} \mathrm{C}\right)$ fixative (same as above). For postfixation, the preparations were incubated in $2 \%$ osmium tetroxide for $60 \mathrm{~min}$, followed by tissue dehydration in a graded ethanol series and in propylene oxide. Specimens were then embedded in resin and sectioned. Seventy-five nanometer sections were stained with lead citrate and uranyl acetate and subsequently imaged with a Hitachi $\mathrm{H} 7000$ transmission electron microscope run at $75 \mathrm{kV}$ using an AMT XR-60 camera and AMT software, version 5.0. 
Statistical analysis. Statistical analyses were performed using unpaired $t$ tests. Error bars in all figures represent SEM.

\section{Results}

\section{Extraction of sterols}

Insects cannot synthesize cholesterol directly; they produce it by conversion of other sterols and acquire it from their diet (Behmer and Nes, 2003). Drosophila contain cholesterol in addition to other sterols (Rietveld et al., 1999; Phillips et al., 2008) and the concentration of cholesterol can be increased by dietary cholesterol (Shreve et al., 2007). Since our larvae were raised on medium containing a source of cholesterol, they should have significant amounts of cholesterol. Despite differences in membrane lipid content, sterol enriched lipid microdomains, analogous to those found in mammalian cells, occur in insect cell membranes (Rietveld et al., 1999). $\mathrm{M} \beta \mathrm{CD}$ can extract cholesterol (Yancey et al., 1995; Jouni et al., 2002; Zhuang et al., 2002; Zamir and Charlton, 2006) and ergosterol (Lagane et al., 2000; Scanlon et al., 2001) from membranes. $\mathrm{M} \beta \mathrm{CD}$ can also disrupt lipid rafts in Drosophila plasma membrane (Eroglu et al., 2003; Gasque et al., 2005).

We measured sterol levels in wildtype Oregon Red $(O R)$ third-instar larval fillet preparations incubated in HL6 saline with or without $10 \mathrm{mM} \mathrm{M} \beta C D$ and found that incubation with $\mathrm{M} \beta \mathrm{CD}$ for 10-30 min significantly reduced sterol levels by $30-40 \%$ (Fig. $1 A$ ). This reduction could be rescued by application of 1:10 cholesterol-M $\beta C D$ complex for 2 min (Fig. $1 B$ ).

\section{Extraction of vesicular sterols prevents recovery of synaptic transmission after endocytic block}

We assessed the effects of membrane sterol depletion on transmitter release by recording the compound EJP generated by tonic-like type $1 \mathrm{~b}$ and phasic-like type 1 s boutons from segment 3 of muscle fiber 6 in third-instar larvae before and after a stimulus train $(10 \mathrm{~Hz}, 12 \mathrm{~min})$ designed to deplete the terminals of synaptic vesicles. In wild-type $(O R)$ controls, EJP amplitude was stable before and after this stimulus protocol (Fig. 2C, closed circles). Application of $10 \mathrm{~mm} \mathrm{M} \beta \mathrm{CD}$ enhanced EJP amplitude by $\sim 50 \%$, and it remained elevated over the course of the stimulus protocol (Fig. $2 C$, open circles), demonstrating that extraction of membrane sterols does not block synaptic transmission under these conditions.

When larval neuromuscular junctions (NMJs) of the shi mutant are stimulated intensely at the nonpermissive temperature of $30^{\circ} \mathrm{C}$, there is a block of synaptic vesicle recycling, which leads to loss of synaptic vesicles (Macleod et al., 2004) and neurotransmitter release (Delgado et al., 2000). This block is reversible and vesicles can reform after return to permissive temperatures $\left(22^{\circ} \mathrm{C}\right)$. We reasoned that $\mathrm{M} \beta \mathrm{CD}$ would target synaptic vesicle sterols better in vesicles trapped on the plasma membrane (Fig.
$2 D$ ) than from vesicles recycling under normal conditions (Fig. $2 A$; see supplemental Discussion, available at www.jneurosci.org as supplemental material). When larval NMJs from shi mutants were subjected to the same stimulus protocol, synaptic transmission was progressively impaired at the restrictive temperature $\left(30^{\circ} \mathrm{C}\right.$ ) but recovered after return to permissive temperature (Fig. $2 E, F$, closed circles). These results are similar to those obtained in previous studies (Koenig and Ikeda, 1999; Delgado et al., 2000). In preparations treated with $10 \mathrm{~mm} \mathrm{M} \beta C D$, there was also loss of EJP amplitude during stimulation at the restrictive temperature, but synaptic transmission did not recover after return to the permissive temperature (Fig. 2 E, F, open circles). However, at the permissive temperature of $22^{\circ} \mathrm{C}$, synaptic transmission was maintained in shi mutants treated with $10 \mathrm{~mm}$ $\mathrm{M} \beta \mathrm{CD}$ during and after a $10 \mathrm{~Hz}$ train for $12 \mathrm{~min}$ (supplemental Fig. $1 A, B$, available at www.jneurosci.org as supplemental material). These results, along with the fact that synaptic transmission was maintained in wild-type larvae treated with $10 \mathrm{~mm} \mathrm{M} \beta C D$ during and after a $10 \mathrm{~Hz}$ train for $12 \mathrm{~min}$ at $30^{\circ} \mathrm{C}$ (Fig. $2 C$ ), demonstrate that the impaired synaptic transmission seen in shi mutants required the action of $\mathrm{M} \beta \mathrm{CD}$ on vesicles trapped at the membrane and was not attributable to the high temperature. 

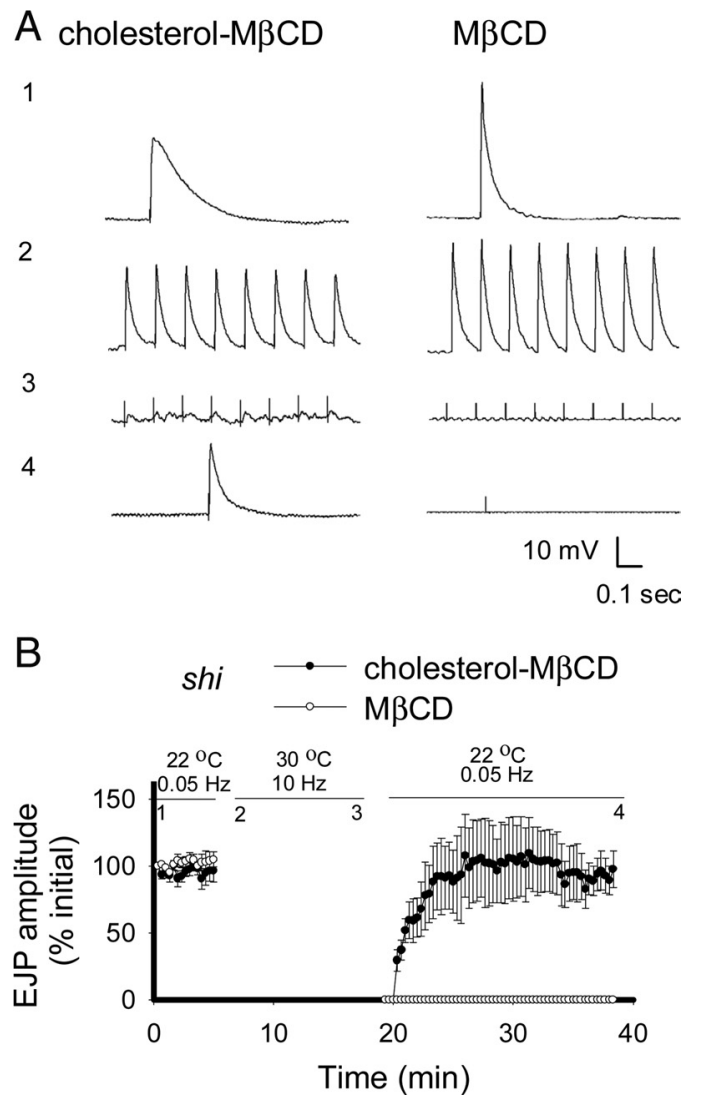

Figure 3. Impairment of synaptic transmission is sterol dependent. $\boldsymbol{A}$, Representative records of EJPs are shown. The numbers next to traces indicate the point at which they occur in the corresponding graphs $(\boldsymbol{B})$. The segmental nerve was stimulated at $0.05 \mathrm{~Hz}$ for $5 \mathrm{~min}$ at $22^{\circ} \mathrm{C}$, and then stimulated at $10 \mathrm{~Hz}$ for $12 \mathrm{~min}$ at $30^{\circ} \mathrm{C}$, followed by stimulation at $0.05 \mathrm{~Hz}$ for $20 \mathrm{~min}$ at $22^{\circ} \mathrm{C}$ to assess recovery. To deplete sterols, $10 \mathrm{~mm} M \beta C D$ was added at the start of recording ( $\boldsymbol{B}$, open circles). Incubation with 1:10 cholesterol-M $\beta C D$ before and during vesicle trapping did not block transmitter release as treatment with $M \beta C D$ did $(n=5)$ ( $B$, closed circles), demonstrating that the effects of $M \beta C D$ were sterol dependent. Preparations were maintained in $\mathrm{HL} 6\left(1 \mathrm{~mm} \mathrm{Ca}^{2+}\right)$ saline for all experiments. Error bars represent SEM.

To determine whether the effects of $\mathrm{M} \beta \mathrm{CD}$ were dependent on its sterol-extracting activity, we applied a 1:10 cholesterolM $\beta C D$ complex to add cholesterol (Churchward et al., 2005). This has previously been used as a control to show cholesterolspecific effects of M $\beta C D$ (Suzuki et al., 2004; Smith et al., 2010). Sterol levels were increased in preparations incubated with this complex (Fig. 1B). Synaptic transmission was again inhibited when shi larvae were stimulated at restrictive temperature in the presence of cholesterol-M $\beta C D$, but recovered completely within 10 min of return to permissive temperature (Fig. $3 A, B$ ). Recovery of release when $\mathrm{M} \beta \mathrm{CD}$ was partially saturated with cholesterol demonstrates that the effects of $\mathrm{M} \beta \mathrm{CD}$ on synaptic transmission require sterol extraction. The failure of 1:10 cholesterol-M $\beta \mathrm{CD}$ to block endocytosis might be attributable to the failure of the complex to extract some other lipophilic membrane constituent that was extracted by $\mathrm{M} \beta \mathrm{CD}$. To examine this possibility, we measured the ability of 1:10 cholesterol-M $\beta C D$ to dissolve another lipophilic compound FM1-43. We found that both $\mathrm{M} \beta \mathrm{CD}$ and 1:10 cholesterol-M $\beta \mathrm{CD}$ take up similar amounts of FM1-43 (see Materials and Methods). Thus, even though M $\beta C D$ may extract some other lipophilic molecule, the block in synaptic transmission is attributable to the extraction of cholesterol, since both $\mathrm{M} \beta \mathrm{CD}$ and 1:10 cholesterol-M $\beta \mathrm{CD}$ were capable of extracting other lipophilic molecules.

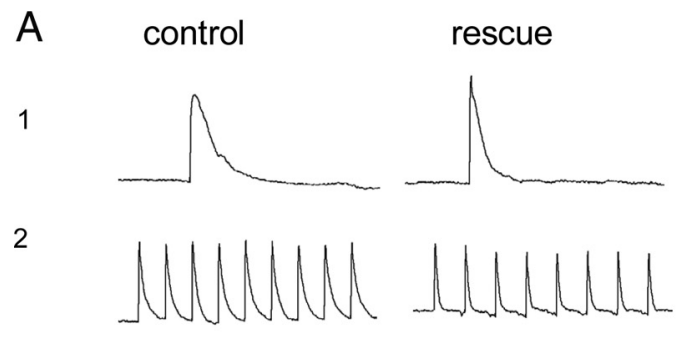

3

4
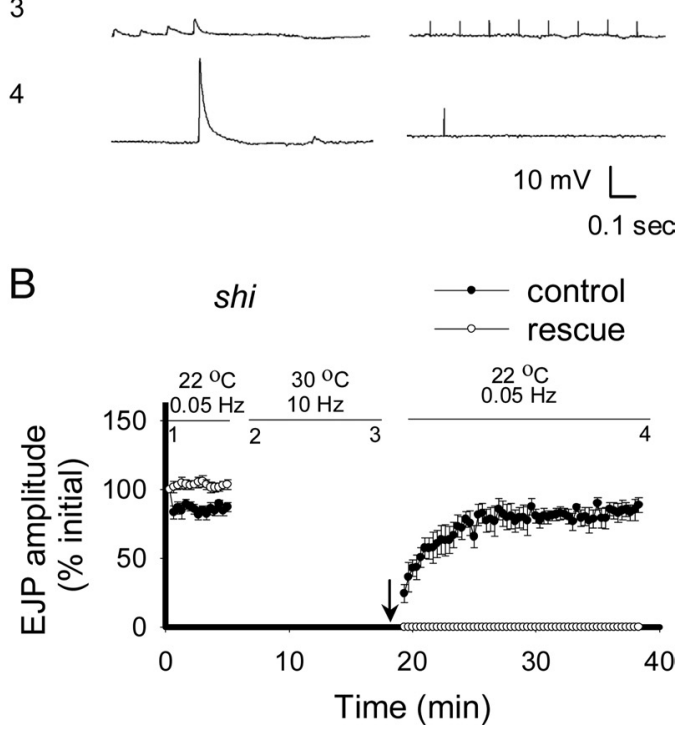

Figure 4. Donation of cholesterol during the recovery phase did not rescue impaired synaptic transmission. $\boldsymbol{A}$, Representative records of EJPs are shown. The numbers next to traces indicate the point at which they occur in the corresponding graphs $(\boldsymbol{B})$. As shown previously, shi preparations stimulated at $10 \mathrm{~Hz}$ at $30^{\circ} \mathrm{C}$ showed loss of transmission that recovered when temperature was returned to the permissive temperature, $22^{\circ} \mathrm{C}(\boldsymbol{A}, \boldsymbol{B}$ closed circles). To determine whether the application of cholesterol could rescue the impaired synaptic transmission seen in preparations depleted of sterols, $M \beta C D$ was applied at the start of the recording and washed off at the end of the $10 \mathrm{~Hz}$ train. The 1:10 cholesterol-M $\beta C D$ complex $(n=5)$ was then applied at $T=19 \mathrm{~min}$ (indicated by arrow) $(\boldsymbol{A}, \boldsymbol{B}$, open circles). Synaptic transmission in preparations depleted of sterols did not recover after the addition of cholesterol. Thus, the effects of vesicular sterol depletion were not reversible. Preparations were maintained in HL6 (1 mM $\left.\mathrm{Ca}^{2+}\right)$ saline for all experiments. Error bars represent SEM.

\section{Synaptic transmission could not be rescued by addition of cholesterol}

In additional experiments, we attempted to reverse the effects of sterol depletion by extracting sterols from trapped vesicles and then using cholesterol-M $\beta \mathrm{CD}$ to donate cholesterol during the recovery phase. This treatment failed to rescue the effects of vesicular sterol depletion in shi terminals (Fig. 4A,B). Application of the water-soluble cholesterol derivatives chobimalt (1 mM) or cholesterol-sulfate $(25 \mu \mathrm{M})$ (both without $\mathrm{M} \beta \mathrm{CD}$ ) during the recovery period also failed to rescue transmission (data not shown) ( $n=4$ for chobimalt and $n=5$ for cholesterol-sulfate). These results, in combination with those showing rapid rescue of sterol levels by cholesterol-M $\beta C D$ complex (Fig. $1 B$ ), demonstrate that application of cholesterol is not sufficient to restore synaptic function once trapped synaptic vesicles have been depleted of sterols for a sustained period.

Impaired vesicle reacidification after cholesterol depletion Multiple modes of endocytosis are sensitive to sterol depletion (Rodal et al., 1999; Subtil et al., 1999; Urs et al., 2005); we therefore investigated the effect of sterol depletion on compensatory 
A
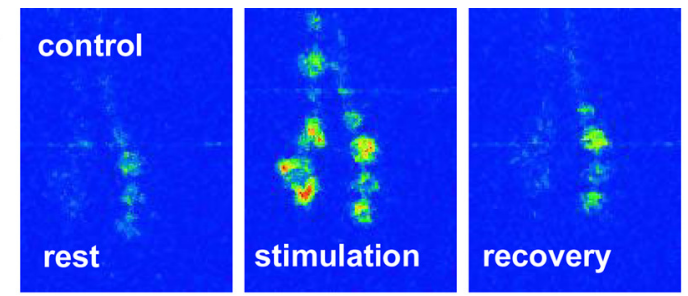

B
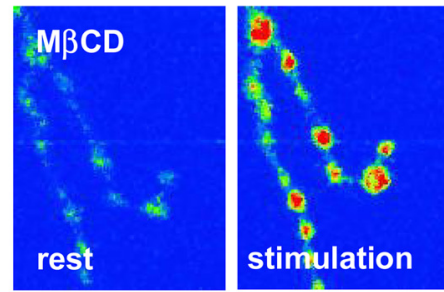

C
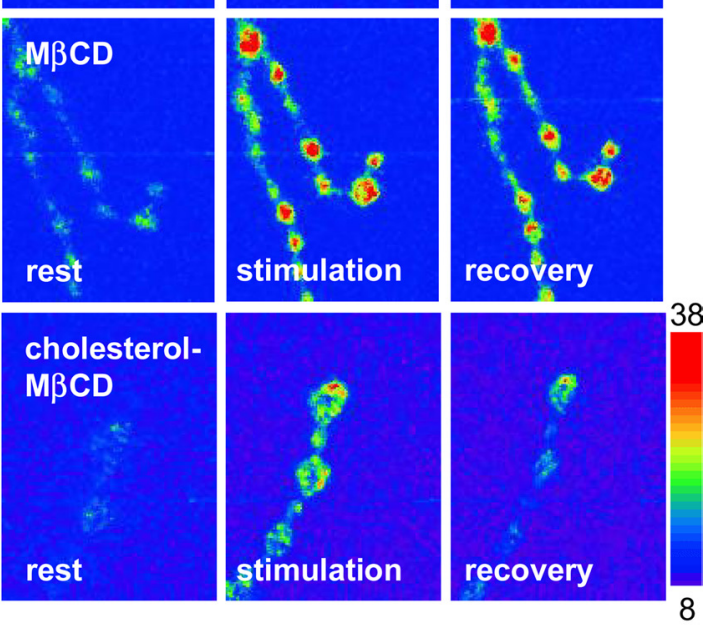

D

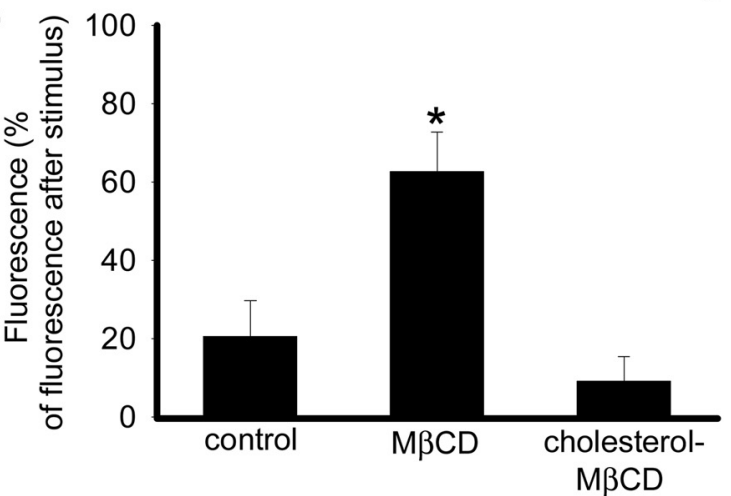

Figure 5. Impaired synaptic vesicle reacidification after sterol extraction from trapped vesicles. $\boldsymbol{A}-\boldsymbol{C}$, Representative images of synaptopHluorin fluorescence in presynaptic terminals of shi; +,UAS-n-Syb-pH,elav ${ }^{3 E 1}$-GAL4/+ preparations in controls $(\boldsymbol{A})$, in the presence of $10 \mathrm{~mm}$ $M \beta C D(B)$, or in the presence of 1:10 cholesterol- $M \beta C D(C)$. The temperature of the saline was raised to $30^{\circ} \mathrm{C}$, and the segmental nerve was stimulated at $10 \mathrm{~Hz}$ for $12 \mathrm{~min}$ to deplete vesicles. The temperature was then lowered back to $22^{\circ} \mathrm{C}$, and stimulation was stopped. During stimulation, the vesicle lumen is exposed to higher extracellular $\mathrm{pH}$ and synaptopHluorin fluoresces. When stimulation ceased, that fluorescence recovered in the control NMJs and in the presence of $1: 10$ cholesterol $-M \beta C D$, but not in the presence of $M \beta C D$. $D$, Fluorescence during the recovery phase ( 50 min after stimulation was stopped) was significantly higher $\left({ }^{*}\right)$ in shi preparations depleted of sterols $(n=5)$ compared with controls $(n=8 ; p<0.05)$. Fluorescence during the recovery phase was not significantly different between 1:10 cholesterol-M $\beta C D(n=5)$ and controls $(n=8 ; p>0.05)$. The lookup table is for images in $A-C$. Fluorescence ( $F$ ) was reported with background $F$ subtracted. The fluorescence response was reported as the change in fluorescence relative to the fluorescence at the end of the stimulus train. Error bars represent SEM.

synaptic vesicle endocytosis by using SynaptopHluorin (n-Syb$\mathrm{pH}$ ), a pH-sensitive GFP (green fluorescent protein) molecule fused to synaptobrevin that has been used to measure synaptic vesicle cycling (Miesenböck et al., 1998). We used the GAL4/UAS system to express n-Syb-pH in shi motor neurons; it does not affect synaptic transmission or nerve terminal morphology (Poskanzer et al., 2003). When shi nerve terminals were stimulated at $10 \mathrm{~Hz}$ for $12 \mathrm{~min}$ at $30^{\circ} \mathrm{C}$ in the absence or presence of $10 \mathrm{~mm}$ $\mathrm{M} \beta \mathrm{CD}, \mathrm{n}$-Syb-pH fluorescence increased (Fig. $5 A, B$ ). Recovery of the EJP response occurs before the recovery of the entire syn-
A

$+/-10 \mathrm{mM} \mathrm{M} \beta \mathrm{CD}$
$30^{\circ} \mathrm{C}$
high $\mathrm{K}^{+}$stimulation
$10 \mu \mathrm{M}$ FM 1-43
Advasep
wash
destain

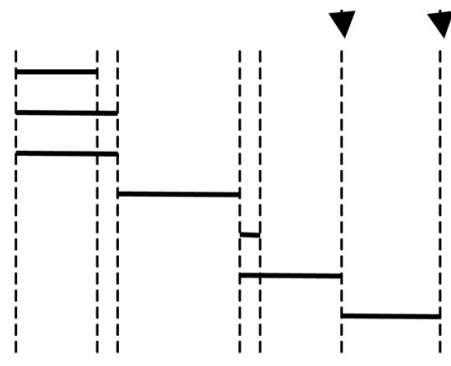

$\begin{array}{llllll}8 & 2 & 20 & 2 & 8 & 10\end{array}$

B
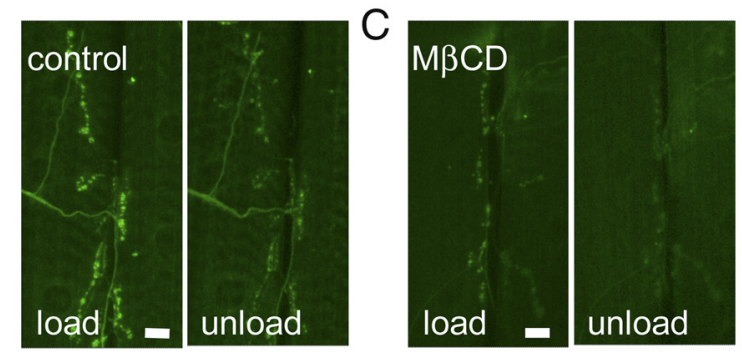

$\mathrm{D}$

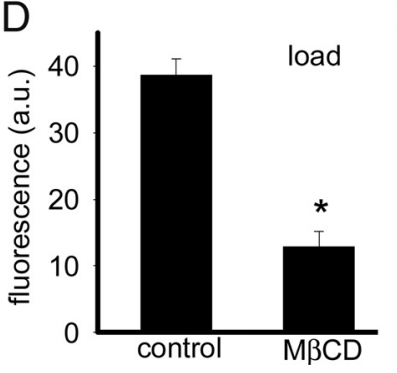

E

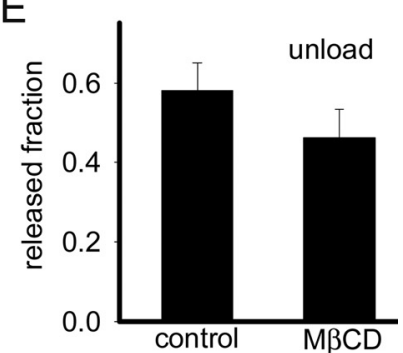

Figure 6. Impaired endocytosis after sterol extraction from trapped synaptic vesicles. $\boldsymbol{A}$, Experimental protocol indicating time at which images were captured (indicated by arrows). $\boldsymbol{B}$, C, Representative images of shi presynaptic terminals loaded with FM1-43 and subsequently unloaded with high $\mathrm{K}^{+}$stimulation. Preparations were stimulated with high $\mathrm{K}^{+}$for $10 \mathrm{~min}$ [without $(\boldsymbol{B})$ or with $10 \mathrm{~mm} \mathrm{M} \beta C D(\boldsymbol{C})$ for first $8 \mathrm{~min}$ ] at $30^{\circ} \mathrm{C}$. To assess endocytosis, preparations were next incubated with $10 \mu \mathrm{MFM} 1-43$ for 20 min at $22^{\circ} \mathrm{C}($ load). Preparations were then washed in $0 \mathrm{~mm} \mathrm{Ca}{ }^{2+} \mathrm{HL} 6$ (with $75 \mu \mathrm{m}$ Advasep-7 for first $2 \mathrm{~min}$ ) for $10 \mathrm{~min}$ to remove extracellular FM1-43 and fluorescence was measured. Then high $\mathrm{K}^{+}$saline was reapplied for 10 min to cause unloading and fluorescence measured again (unload). $\boldsymbol{D}$, shi presynaptic terminals depleted of vesicular sterol took up significantly less $\left(^{*}\right)$ FM1-43 than shi controls $(n=6 ; p<$ 0.01). $\boldsymbol{E}$, A similar fraction of FM1-43 was released in control and sterol depleted shi presynaptic terminals in response to high $\mathrm{K}^{+}$stimulation for $10 \mathrm{~min}$, demonstrating that some of the endocytosed membrane is capable of exocytosis $(n=6 ; p>0.05)$. Fluorescence $(F)$ was reported with background $F$ subtracted. Scale bars, $10 \mu \mathrm{m}$. Error bars represent SEM.

aptic vesicle pool at adult shibire synapses (Koenig and Ikeda, 1999). We were unable to detect significant recovery of n-Syb-pH fluorescence after $10 \mathrm{~min}$ of recovery in controls $(92.2 \pm 19.2 \%$ of maximum; $n=8)$. However, after 50 min fluorescence had mostly recovered in controls (Fig. $5 A, D$ ) but remained elevated in shi preparations depleted of vesicular sterols (Fig. $5 B, D$ ). In the presence of 1:10 cholesterol-M $\beta C D$, the fluorescence returned similarly to controls (Fig. $5 C, D$ ). These data demonstrate that synaptic vesicle recycling is impaired at a step before vesicle reacidification.

\section{Impaired FM1-43 uptake after vesicular sterol extraction}

The lack of recovery of n-Syb-pH fluorescence could be attributable to impaired vesicle reacidification or recycling. To examine further the role of vesicular sterols in synaptic vesicle cycling, we used the lipophilic styryl dye FM1-43 (Betz and Bewick, 1992). Synaptic vesicles were depleted in shi terminals by stimulation 
A membrane sterol depletion

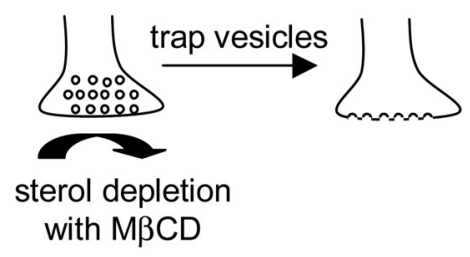

C

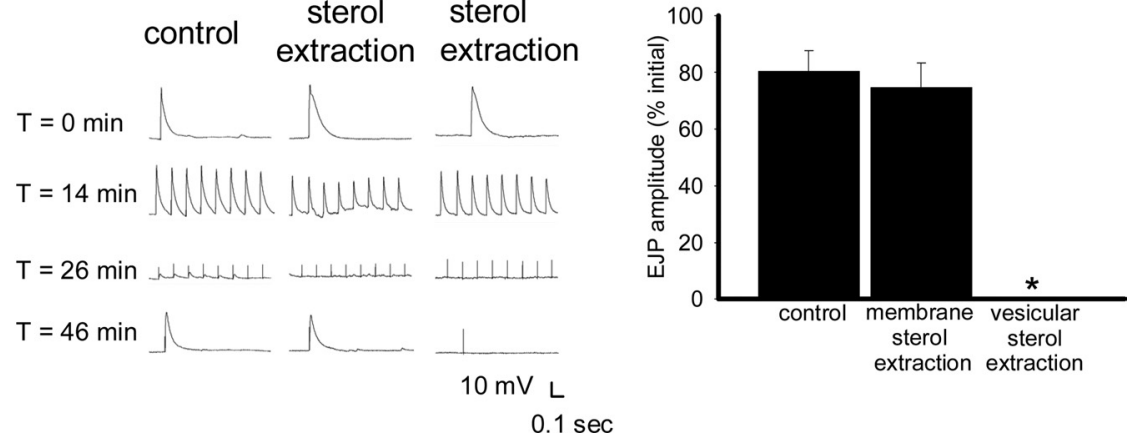

Figure 7. Extraction of membrane sterols before trapping synaptic vesicles does not block recovery of synaptic transmission. $A$, Schematic of sterol extraction from the plasma membrane of a presynaptic terminal by $M \beta C D$ applied at $30^{\circ} \mathrm{C}$ before $10 \mathrm{~Hz}$ stimulation. Synaptic vesicles were then trapped on the sterol-depleted plasma membrane during $10 \mathrm{~Hz}$ stimulation. $\boldsymbol{B}$, Schematic of synaptic vesicles being trapped on the plasma membrane of a presynaptic terminal during stimulation at $10 \mathrm{~Hz}, 30^{\circ} \mathrm{C}$. Subsequently, sterols were extracted by $M \beta C D$ from trapped synaptic vesicles. C, shi preparations were maintained in $\mathrm{HL} 6\left(1 \mathrm{mM} \mathrm{Ca}^{2+}\right)$ saline for all experiments. The segmental nerve was stimulated at $0.05 \mathrm{~Hz}$ for $12 \mathrm{~min}$ at $30^{\circ} \mathrm{C}$, followed by $10 \mathrm{~Hz}$ stimulation for $12 \mathrm{~min}$ at $30^{\circ} \mathrm{C}$, and then stimulated at $0.05 \mathrm{~Hz}$ for $20 \mathrm{~min}$ at $22^{\circ} \mathrm{C}$ to assess recovery of synaptic transmission. Left column, Synaptic transmission was completely abolished in shi mutants $(n=3)$ in response to $10 \mathrm{~Hz}$ stimulation at $30^{\circ} \mathrm{C}$, but after $20 \mathrm{~min}$ at $22^{\circ} \mathrm{C}$ had recovered. Middle column, When $M \beta C D$ was applied during the $0.05 \mathrm{~Hz}$ stimulation and then washed off before the $10 \mathrm{~Hz}$ stimulation, synaptic transmission recovered at $22^{\circ} \mathrm{C}$. Right column, When $M \beta C D$ was applied during the $10 \mathrm{~Hz}$ stimulation, and then washed off, there was no recovery at $22^{\circ} \mathrm{C}$. $D$, Measurements of EJP amplitude showed that recovery of synaptic transmission was not significantly impaired in shi mutants that were treated with $10 \mathrm{~mm} \mathrm{M} \beta C D$ before the $10 \mathrm{~Hz}$ train $(n=5 ; p>0.05)$. In contrast, recovery of synaptic transmission was significantly impaired $\left(^{*}\right)$ in shi mutants that were treated with $10 \mathrm{~mm} \mathrm{M} \beta C D$ during the $10 \mathrm{~Hz}$ train $(n=$ $4 ; p<0.01)$. Error bars represent SEM.

with $90 \mathrm{mM} \mathrm{K}^{+}$saline for $8 \mathrm{~min}$ at $30^{\circ} \mathrm{C}$ in the absence or presence of $10 \mathrm{~mm} \mathrm{M} \beta \mathrm{CD}$ (Fig. $6 A-C$ ). Preparations were then incubated with $10 \mu \mathrm{M}$ FM1-43 for $20 \mathrm{~min}$ at $22^{\circ} \mathrm{C}$, washed with Advasep-7 (a cyclodextrin that does not extract cholesterol) to remove plasma membrane-bound FM1-43 (Kay et al., 1999), washed for an additional $8 \mathrm{~min}$ in calcium-free HL6, and imaged. Consistent with our n-Syb-pH data, we found a 67\% reduction in FM1-43 uptake in shi preparations depleted of vesicular sterols compared with controls (Fig. 6D), indicating a reduction of compensatory endocytosis after sterol depletion. FM1-43 uptake by liposomes is dependent on cholesterol (Wang et al., 2006); however, another study found no evidence for this in cultured hippocampal neurons (Suzuki et al., 2004). To confirm that extraction of sterols did not affect the ability of FM1-43 to bind to membranes, we measured the fluorescence of muscle fibers in control and $\mathrm{M} \beta \mathrm{CD}$-treated preparations and found that they had similar fluorescence levels. Unlike FM1-43, FM4-64 uptake by liposomes was not cholesterol dependent (Wang et al., 2006). We found that FM4-64 uptake was significantly impaired in M $\beta C D$-treated preparations ( $6.99 \pm 1.26$ a.u.; $n=5)$ compared with controls (27.18 \pm 3.59 a.u.; $n=5$ ), similar to our FM1-43 experiments, demonstrating that the impaired FM1-43 uptake is attributable to reduced membrane retrieval and not attributable to the inability of FM1-43 to bind to membranes.
Both preparations depleted of vesicular sterols and their controls released a similar fraction of FM1-43 (Fig. 6E) and FM4-64 (control, $0.59 \pm 0.07, n=5 ; \mathrm{M} \beta \mathrm{CD}, 0.48 \pm$ $0.11, n=5)$ after a second, unloading stimulus with high $\mathrm{K}^{+}$. Therefore, after vesicular sterol extraction, the endocytosed membrane is capable of exocytosis in response to high $\mathrm{K}^{+}$stimulation.

\section{Extraction of membrane sterols before trapping synaptic vesicles does not block synaptic transmission or impair endocytosis}

In the previous experiments, we demonstrated that synaptic vesicles must be trapped at the plasma membrane for sterol depletion to block synaptic function. To investigate the importance of plasma membrane sterols, we treated preparations with $10 \mathrm{~mm} \mathrm{M} \beta \mathrm{CD}$ at $30^{\circ} \mathrm{C}$ for 12 $\mathrm{min}$, and then washed it out and subjected the preparation to the vesicle-trapping protocol (Fig. 7A). Membrane sterol extraction in shi terminals at $30^{\circ} \mathrm{C}$ for 12 min before the $10 \mathrm{~Hz}$ train did not block recovery of synaptic transmission when preparations were subsequently subjected to a vesicle depletion-recovery protocol (Fig. 7C,D). Vesicular sterol extraction (Fig. $7 B$ ) in shi terminals only during the $10 \mathrm{~Hz}$ train for $12 \mathrm{~min}$ at $30^{\circ} \mathrm{C}$ was sufficient to block subsequent recovery of synaptic transmission at $22^{\circ} \mathrm{C}$ (Fig. $7 C, D$ ). There were no significant differences in FM1-43 uptake or release between preparations depleted of only membrane sterols and controls (Fig. 8), confirming that endocytosis was not impaired by sterol depletion before vesicle trapping. These results demonstrate that depletion of the plasma membrane sterol pool before trapping vesicles does not prevent membrane reuptake or the recovery of synaptic transmission and suggest that the plasma membrane sterol pool does not play an important role in synaptic vesicle recycling.

\section{Synaptic terminals depleted of vesicular sterols contain few synaptic vesicles}

Our results demonstrate that recovery of synaptic transmission is prevented by depletion of sterols from trapped vesicles but that a reduced amount of endocytosis persists and that this internalized membrane can still undergo exocytosis. To investigate whether this membrane reuptake represents the formation of synaptic vesicles or some endosomal intermediary structure, we performed electron microscopy. We compared shi preparations that were incubated in $1 \mathrm{mM} \mathrm{Ca}^{2+}$ HL6 saline with or without $10 \mathrm{~mm}$ $\mathrm{M} \beta \mathrm{CD}$ for $20 \mathrm{~min}$ at $22^{\circ} \mathrm{C}$. There were no apparent differences in the ultrastructure of shi presynaptic terminals of preparations depleted of membrane sterols and controls (Fig. 9A,D). To confirm that synaptic vesicles could be completely depleted in the presence of $10 \mathrm{mM} \mathrm{M} \beta C D$, we immediately fixed shi preparations after stimulation at $10 \mathrm{~Hz}$ for $12 \mathrm{~min}$ at the restrictive temperature. In both $\mathrm{M} \beta \mathrm{CD}$-treated and untreated samples, our stimu- 
A

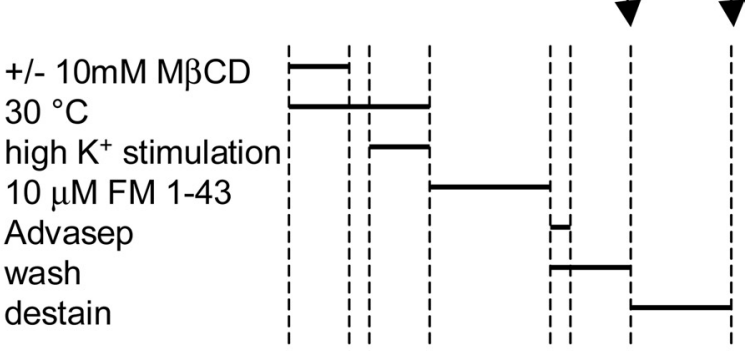

$8210 \quad 20 \quad 2 \quad 810 \mathrm{~min}$
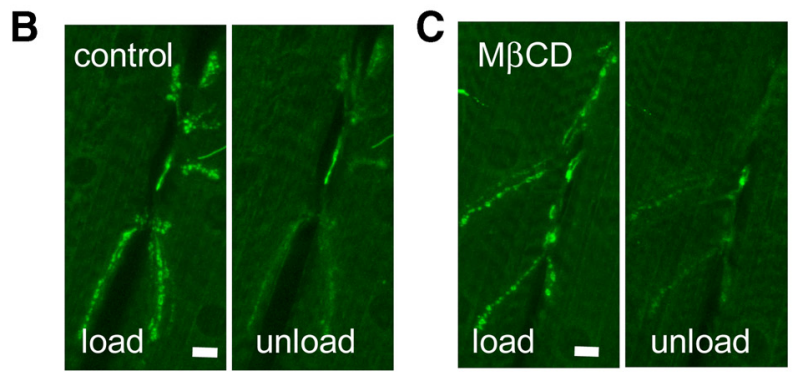

D
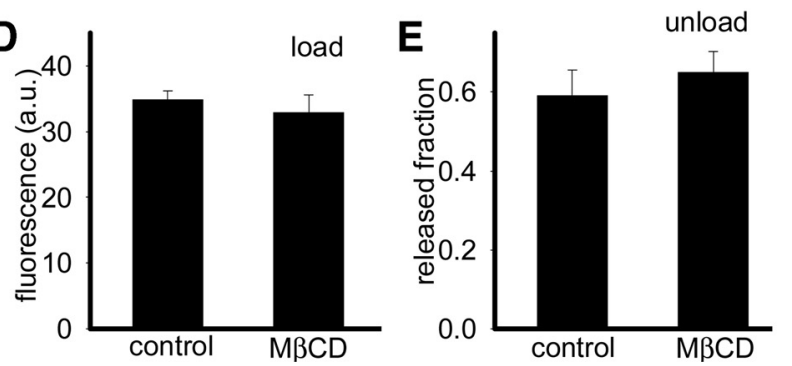

Figure 8. Depletion of only membrane sterol does not affect uptake of FM1-43. $\boldsymbol{A}$, Experimental protocol indicating time at which images were captured (indicated by arrows). $\boldsymbol{B}, \boldsymbol{C}$, Representative images of shi presynaptic terminals loaded with FM1-43 and subsequently unloaded with high $\mathrm{K}^{+}$stimulation. Preparations were incubated with HL6 [without $(\boldsymbol{B})$ or with $10 \mathrm{~mm} \mathrm{M} \beta C D(C)$ for first $8 \mathrm{~min}]$ for $10 \mathrm{~min}$ at $30^{\circ} \mathrm{C}$ before stimulation. Preparations were then stimulated with high $\mathrm{K}^{+}$(no $\mathrm{M} \beta C \mathrm{CD}$ ) for 10 min at $30^{\circ} \mathrm{C}$. To assess synaptic vesicle endocytosis, we incubated preparations with $10 \mu \mathrm{m} \mathrm{FM1-43} \mathrm{for} 20 \mathrm{~min}$ at $22^{\circ} \mathrm{C}$ and then washed in $0 \mathrm{~mm}$ $\mathrm{Ca}^{2+}$ HL6 (with $75 \mu \mathrm{m}$ Advasep-7 for first 2 min to remove extracellular FM1-43) for $10 \mathrm{~min}$. D, $\boldsymbol{E}$, Measurements of fluorescence showed that control and membrane sterol depleted shi presynaptic terminals took up and released similar amounts of FM1-43 $(n=5 ; p>0.05)$, demonstrating that synaptic vesicle endocytosis is not impaired when membrane sterols are depleted before trapping synaptic vesicles at the plasma membrane. Fluorescence $(F)$ was reported with background $F$ subtracted. Scale bars, $10 \mu \mathrm{m}$. Error bars represent SEM.

lation protocol resulted in the complete depletion of synaptic vesicles from the terminals (Fig. 9B,E). To assess recovery, shi preparations were depleted and then allowed to recover for 20 min at $22^{\circ} \mathrm{C}$ before fixation. Consistent with other studies (Koenig and Ikeda, 1989, 1996), we found recovery of synaptic vesicles in these preparations (Fig. 9C), although at lower levels than the unstimulated NMJ (Fig. 9A). The recovery of synaptic transmission is faster than the time required for the entire synaptic vesicle pool to reform because single $1 \mathrm{~b}$ and $1 \mathrm{~s}$ boutons only release approximately four quanta per impulse during low-frequency stimulation (Dason et al., 2009); thus, a full complement of synaptic vesicles is not needed for recovery of synaptic transmission to occur. In shi preparations that were depleted of vesicular sterols and fixed after the recovery period at $22^{\circ} \mathrm{C}$, only a few synaptic vesicles were apparent, but several endosomes were observed (Fig. 9F). There were significantly more endosomes per section in preparations depleted of vesicular sterols $(3.75 \pm 0.81$; $n=20 ; p<0.01)$ than controls $(0.21 \pm 0.12 ; n=19)$ and no significant difference in the area of boutons analyzed (depleted of vesicular sterols, 992,668 $\pm 157,130 \mathrm{~nm}^{2}$; controls, 1,092,586 \pm $\left.208,934 \mathrm{~nm}^{2} ; p=0.8946\right)$. These endosomal structures appear in shi synapses in early stages of recovery after depletion, but disappear as synaptic vesicles begin to form (Koenig and Ikeda, 1989). Our results demonstrate that limited formation of endosomes occurs after vesicular sterol depletion, but the formation of synaptic vesicles is impaired.

\section{Discussion}

Our data can be summarized as follows; $\mathrm{M} \beta \mathrm{CD}$ extracts sterols from Drosophila larval fillet preparations, and cholesterol$\mathrm{M} \beta \mathrm{CD}$ can replace the lost sterol. Sterol extraction under normal conditions does not impair synaptic function, but if sterols are extracted from synapses during endocytic blockade then recovery of synaptic transmission after removal of the endocytic block is prevented. This effect is attributable to the sterol-extracting activity of $\mathrm{M} \beta \mathrm{CD}$ because $\mathrm{M} \beta \mathrm{CD}$ partially saturated with cholesterol does not block transmitter release. This block in transmitter release is attributable to the extraction of sterols, since both $\mathrm{M} \beta \mathrm{CD}$ and 1:10 cholesterol-M $\beta \mathrm{CD}$ take up similar amounts of the small lipophilic dye FM1-43, demonstrating that the effects of $\mathrm{M} \beta \mathrm{CD}$ are not attributable to the extraction of some other lipophilic molecule. The block of transmitter release was not reversible since the application of cholesterol-M $\beta \mathrm{CD}$ did not allow recovery. Two measures of endocytosis, recovery of n-Syb-pH fluorescence and uptake of FM1-43 or FM4-64, showed that the impaired transmitter release was attributable to a block in endocytosis. Recovery of transmitter release and endocytosis were normal when $\mathrm{M} \beta \mathrm{CD}$ was applied to shi synapses before vesicle trapping. Ultrastructural analysis showed that shi synapses treated with or without $\mathrm{M} \beta \mathrm{CD}$ could be depleted of vesicles; the vesicle population recovered in shi synapses not treated with $\mathrm{M} \beta \mathrm{CD}$ at permissive temperatures, but the vesicle population did not recover in shi synapses treated with $\mathrm{M} \beta \mathrm{CD}$.

\section{Sterols and transmitter release}

Cholesterol depletion increases spontaneous neurotransmitter release and impairs evoked release from the NMJs of crustaceans (Zamir and Charlton, 2006) and from the synapses of cultured hippocampal (Wasser et al., 2007) and cerebellar neurons (Smith et al., 2010). The effect of acute sterol depletion on synaptic function in flies has not previously been studied. We found that sterol extraction from larval NMJs enhanced evoked (Fig. $2 B, C$ ) and spontaneous neurotransmitter release (supplemental Fig. 2A, $B$, available at www.jneurosci.org as supplemental material). The impairment of synaptic transmission after sterol extraction at the crayfish NMJ is attributable to failure of action potential propagation; EPSCs generated by focal stimulation of synaptic terminals were larger after $\mathrm{M} \beta \mathrm{CD}$ treatment (Zamir and Charlton, 2006). The increase in EPSC amplitude we observed after $M \beta C D$ application in this study suggests that this treatment does not impair action potential propagation to release sites in Drosophila motor neurons. The increase in the number of released quanta is somewhat different from observations on vertebrates. Although sterol extraction reduces the amplitude of EPSCs in cultured hippocampal and cerebellar neurons (Wasser et al., 2007; Smith et al., 2010), it also reduces the paired-pulse ratio, suggesting increased release probability (Smith et al., 2010). Given the smaller size of vesicle pools at mammalian central synapses compared with invertebrate NMJs (for review, see Rizzoli and Betz, 2005), it is possible that the reduction in EPSC amplitude seen in vertebrate preparations is caused by defective vesicle recycling result- 

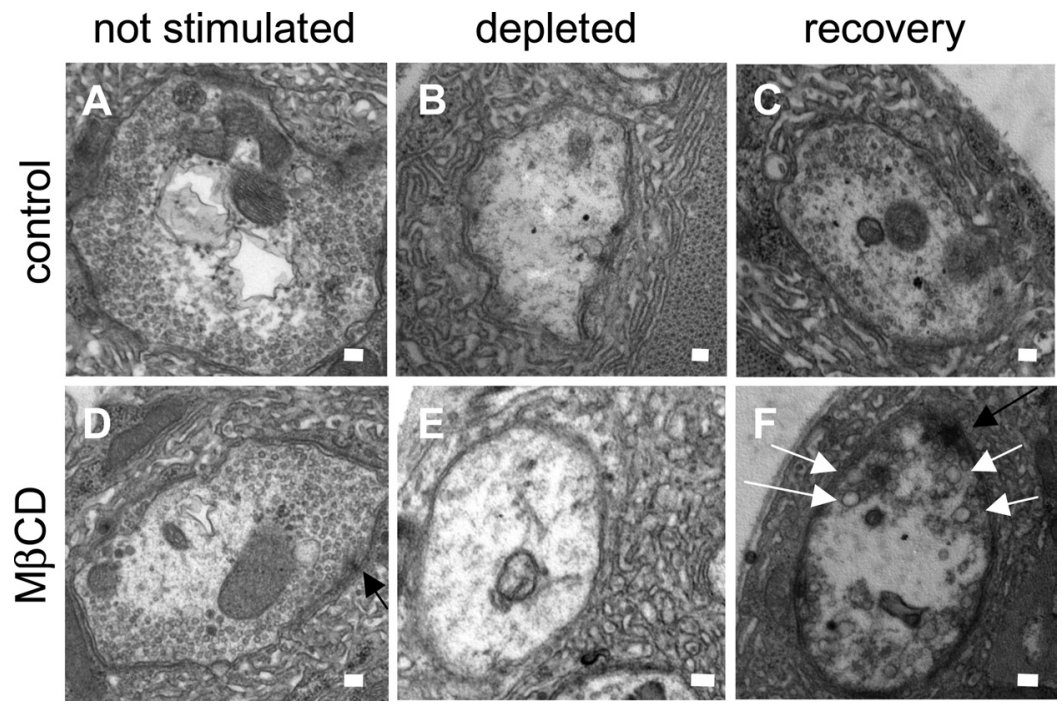

Figure 9. Limited reformation of endosomes but not synaptic vesicles after extraction of sterols from trapped vesicles. $\boldsymbol{A}$, $D$, Unstimulated shi preparations contain numerous synaptic vesicles when incubated with $(n=11)$ or without $(n=6) 10$ $\mathrm{mm} M \beta C D$ for $20 \mathrm{~min}$ at $22^{\circ} \mathrm{C}$ and then fixed at $22^{\circ} \mathrm{C} . \boldsymbol{B}, \boldsymbol{E}$, Stimulation at $10 \mathrm{~Hz}$ for $12 \mathrm{~min}$ at $30^{\circ} \mathrm{C}$ and fixation at $30^{\circ} \mathrm{C}$ leads to a complete depletion of synaptic vesicles in shi presynaptic terminals treated with $(n=16)$ or without $(n=25) 10 \mathrm{~mm}$ $M \beta C D$. C, When shi preparations not treated with $10 \mathrm{~mm} M \beta C D$ were stimulated at $10 \mathrm{~Hz}$ for $12 \mathrm{~min}$ at $30^{\circ} \mathrm{C}$, and then returned to $22^{\circ} \mathrm{C}$ for $20 \mathrm{~min}$, and fixed at $22^{\circ} \mathrm{C}$, synaptic vesicles reformed $(n=12)$. $\boldsymbol{F}$, In contrast, when shi presynaptic terminals treated with $10 \mathrm{~mm} \mathrm{M} \beta C D$ were stimulated at $10 \mathrm{~Hz}$ for $12 \mathrm{~min}$ at $30^{\circ} \mathrm{C}$, and then returned to $22^{\circ} \mathrm{C}$ for $20 \mathrm{~min}$ and fixed at $22^{\circ} \mathrm{C}$, only a few synaptic vesicles were able to reform $(n=15)$. Thus, synaptic vesicle endocytosis is severely impaired. In addition, numerous endosomes were also observed. The white arrows indicate endosomes. The black arrows indicate active zones. $n=$ the number of nerve terminals analyzed. For each condition, two to four different preparations were examined. Scale bars, $100 \mathrm{~nm}$.

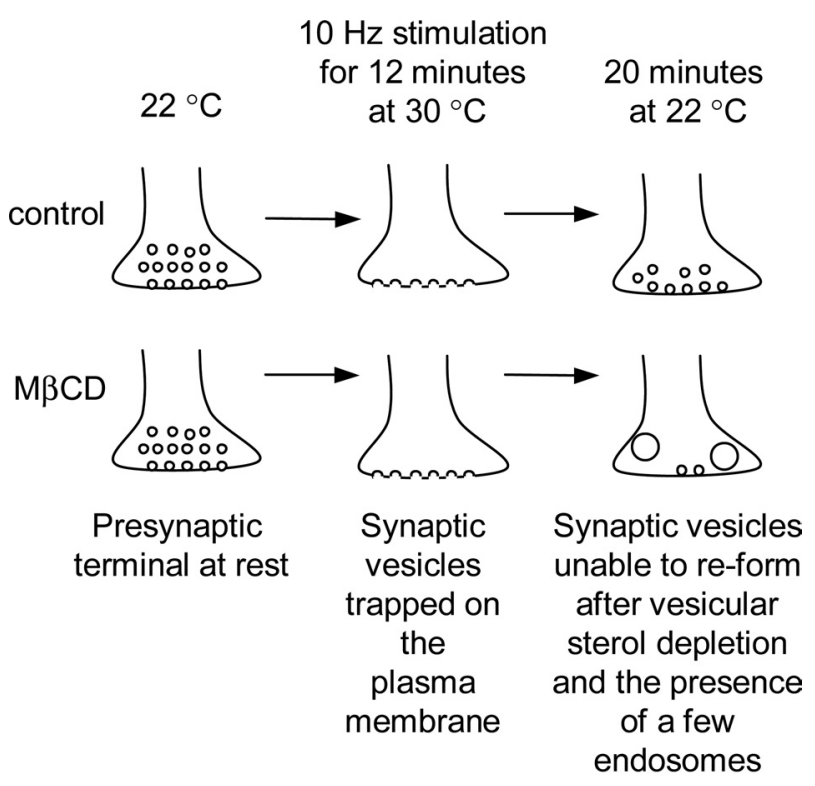

Figure 10. Vesicular sterols are required for compensatory synaptic vesicle endocytosis. The entire pool of synaptic vesicles in shibire presynaptic terminals can be depleted and trapped on the plasma membrane in response to high-frequency stimulation for several minutes at nonpermissive temperatures $\left(30^{\circ} \mathrm{C}\right)$. This depletion is reversible and synaptic vesicles can reform at permissive temperatures $\left(22^{\circ} \mathrm{C}\right)$. The formation of synaptic vesicles is preceded by the appearance of endosomes. These endosomal structures disappear as synaptic vesicles reform. When vesicular sterols were extracted from trapped synaptic vesicles, only a few synaptic vesicles were apparent and some endosomes were still present after $20 \mathrm{~min}$. Thus, extraction of vesicular sterols impairs clathrin-mediated endocytosis and the formation of synaptic vesicles from endosomes. ing in a significant reduction in the size of the releasable vesicle pool. The mechanism by which sterol depletion increases transmitter release probability at the larval NMJ is beyond the scope of this study, but changes in the activity of kinases or the modulation of ion channels are both possible mechanisms. Sterol depletion has been shown to increase the activity of staurosporine-sensitive kinases (Burgos et al., 2004; Cabrera-Poch et al., 2004) and the increased release probability observed in cultured cerebellar cells after sterol depletion is blocked by staurosporine (Smith et al., 2010). Sterol depletion also alters the localization and activity of $\mathrm{K}^{+}$ (Gasque et al., 2005; Shmygol et al., 2007) and $\mathrm{Ca}^{2+}$ channels (Taverna et al., 2004; Toselli et al., 2005), which in turn could affect transmitter release.

\section{Vesicular sterol depletion \\ blocks endocytosis}

In the terminals of shi mutants recovering from synaptic vesicle depletion, vesicles reform both through direct clathrinmediated endocytosis at active zones and from endosomal intermediaries at nonactive zone sites (Koenig and Ikeda, 1989, 1996). A bulk endocytic pathway functions during periods of increased neuronal activity to increase the rate of membrane reuptake in other preparations as well (Clayton et al., 2008; Clayton and Cousin, 2009). Our results demonstrate a clear inhibition of vesicle recycling when sterols are extracted from vesicles stalled in the plasma membrane.

We designed our experiments so that FM1-43 (or FM4-64) and $M \beta C D$ were not applied at the same time because $\beta$-cyclodextrin binds FM1-43 (Kay et al., 1999), and we found this also occurs with $\mathrm{M} \beta \mathrm{CD}$ (supplemental Fig. 3, available at www.jneurosci.org as supplemental material). Binding of FM1-43 to M $\beta C D$ would have reduced or eliminated the uptake of FM1-43. We found that total FM1-43 uptake is reduced by $67 \%$ after sterol depletion from trapped vesicles (Fig. 6) and similar results were obtained with FM4-64. Recovery of Syb-pH fluorescence was also blocked when vesicular sterols were extracted. Some endosomal structures were observed after sterol depletion, but the number of synaptic vesicles was severely reduced (Fig. $9 F)$. A recent study found that synaptic membrane proteins are present in microdomains on endosomes that likely persist during membrane recycling and that sterol depletion by $\mathrm{M} \beta \mathrm{CD}$ disintegrates these microdomains (Geumann et al., 2010). These microdomains may be required for synaptic vesicles to reform from endosomes. Overall, we found a reduction in vesicular sterols did not entirely block bulk endocytosis and the most striking effect of vesicular sterol depletion is impairment of synaptic vesicle reformation (Fig. 10).

Several steps in clathrin-dependent endocytosis are sensitive to membrane sterol content. Clathrin heavy chain and AP-2 membrane binding are dependent on cholesterol content of neuronal membranes (Jia et al., 2006), possibly because sterols are required to aggregate the phosphoinositides that recruit AP-2 and clathrin to sites of endocytosis (Milosevic et al., 2005). Inhi- 
bition of clathrin function by FlAsH-FALI-mediated clathrin heavy or light chain photoinactivation, results in a similar phenotype to that which we have observed after vesicular sterol depletion; synaptic vesicle reformation is blocked, but formation of endosomal intermediates persists (Heerssen et al., 2008; Kasprowicz et al., 2008). Several synaptic vesicle membrane proteins (synaptotagmin, synaptophysin, and V-ATPase) can be photocrosslinked to cholesterol (Thiele et al., 2000) and may be mislocalized after vesicular sterol extraction. Both synaptotagmin and synaptobrevin are required for synaptic vesicle endocytosis (Poskanzer et al., 2003; Deák et al., 2004). Extraction of sterols from isolated synaptosomes inhibits formation of a synaptophysin/synaptobrevin complex that may be important in targeting some proteins to synaptic vesicles (Mitter et al., 2003); however, Drosophila lack synaptophysin (Littleton, 2000; Lloyd et al., 2000), so sterols are required at additional steps of the endocytic process. Our observations are consistent with studies demonstrating that the absence of proteins involved in cholesterol homeostasis results in alterations to the number and structure of synaptic vesicles. A change in synaptic vesicle size has been observed in cerebellar synaptosomes isolated from Niemann-Pick C1-deficient mice (Karten et al., 2006), and the number of synaptic vesicles is reduced in the motor cortex of cholesterol transporter ABCA1-deficient mice (Karasinska et al., 2009).

Under control conditions, acute extraction of plasma membrane sterols did not impair FM1-43 loading or unloading in our experiments (Fig. 8), which is consistent with a previous study on cultured hippocampal and cortical neurons (Suzuki et al., 2004). If plasma membrane sterols are required to maintain a reservoir of surface proteins that interchange with proteins from released synaptic vesicles before endocytosis occurs or if such an interchange between membrane and vesicular sterols occurs, one would expect exocytosis, endocytosis, or both to be impaired when membrane sterols are extracted before depletion of the entire synaptic vesicle pool. We found that trapping synaptic vesicles in sterol-depleted plasma membranes of presynaptic terminals did not impair subsequent endocytosis during the recovery phase. Thus, it seems unlikely that plasma membrane sterols maintain this reservoir of proteins or that an interchange occurs between membrane and vesicular sterols during recycling. If vesicles had lost a critical amount of sterol to the depleted plasma membrane, then recovery would not have occurred. The lack of sterol mixing may explain how syntaxin-1A, which may be concentrated in cholesterol-dependent clusters (Lang et al., 2001), is maintained in the plasma membrane and excluded from synaptic vesicles during endocytosis (Mitchell and Ryan, 2004).

\section{Block of endocytosis could not be rescued}

Effects on neurotransmitter release of $\mathrm{M} \beta \mathrm{CD}$-induced cholesterol depletion were reversed when membrane cholesterol was restored (Zamir and Charlton, 2006; Wasser et al., 2007). In CHO and HeLa cells, blockade of constitutive or receptor-triggered endocytosis by cholesterol depletion was restored by addition of cholesterol (Subtil et al., 1999; Urs et al., 2005). In contrast, a striking feature of our data is that the block of endocytosis caused by vesicular sterol extraction cannot be rescued by application of cholesterol-M $\beta \mathrm{CD}$ complex or two other water-soluble cholesterol compounds during the time course of our experiments. We speculate that it may not be possible to reform synaptic vesicles once their constituents are dispersed in the plasma membrane. Since Drosophila membranes can form rafts (Rietveld et al., 1999), and synaptic vesicles have raft-like properties (Martin, 2000; Yoshinaka et al., 2004; Jia et al., 2006; Lv et al., 2008), the many adapter proteins involved in endocytosis (for review, see Dittman and Ryan, 2009) might disperse (Geumann et al., 2010) or it might be energetically difficult to reinsert cholesterol into the densely packed membranes of vesicles.

In summary, we used a temperature-sensitive shi mutant to trap synaptic vesicles at the plasma membrane and extracted sterols from synaptic vesicles in live presynaptic terminals. Our results demonstrate that the high sterol content of vesicles is essential for synaptic vesicle endocytosis.

\section{References}

Behmer ST, Nes WD (2003) Insect sterol nutrition and physiology: a global perspective. Adv In Insect Phys 31:1-72.

Betz WJ, Bewick GS (1992) Optical analysis of synaptic vesicle recycling at the frog neuromuscular junction. Science 255:200-203.

Burgos PV, Klattenhoff C, de la Fuente E, Rigotti A, González A (2004) Cholesterol depletion induces PKA-mediated basolateral-to-apical transcytosis of the scavenger receptor class B type I in MDCK cells. Proc Natl Acad Sci U S A 101:3845-3850.

Cabrera-Poch N, Sánchez-Ruiloba L, Rodríguez-Martínez M, Iglesias T (2004) Lipid raft disruption triggers protein kinase $\mathrm{C}$ and Src-dependent protein kinase D activation and Kidins 220 phosphorylation in neuronal cells. J Biol Chem 279:28592-28602.

Churchward MA, Rogasevskaia T, Höfgen J, Bau J, Coorssen JR (2005) Cholesterol facilitates the native mechanism of $\mathrm{Ca}^{2+}$-triggered membrane fusion. J Cell Sci 118:4833-4848.

Clayton EL, Cousin MA (2009) The molecular physiology of activitydependent bulk endocytosis of synaptic vesicles. J Neurochem 111:901-914.

Clayton EL, Evans GJ, Cousin MA (2008) Bulk synaptic vesicle endocytosis is rapidly triggered during strong stimulation. J Neurosci 28:6627-6632.

Dason JS, Romero-Pozuelo J, Marin L, Iyengar BG, Klose MK, Ferrús A, Atwood HL (2009) Frequenin/NCS-1 and the $\mathrm{Ca}^{2+}$ channel $\alpha_{1}$-subunit co-regulate synaptic transmission and nerve terminal growth. J Cell Sci 122:4109-4121.

Deák F, Schoch S, Liu X, Südhof TC, Kavalali ET (2004) Synaptobrevin is essential for fast synaptic-vesicle endocytosis. Nat Cell Biol 6:1102-1108

Delgado R, Maureira C, Oliva C, Kidokoro Y, Labarca P (2000) Size of vesicle pools, rates of mobilization, and recycling at neuromuscular synapses of a Drosophila mutant, shibire. Neuron 28:941-953.

Dittman J, Ryan TA (2009) Molecular circuitry of endocytosis at nerve terminals. Annu Rev Cell Dev Biol 25:133-160.

Eroglu C, Brugger B, Wieland F, Sinning I (2003) Glutamate-binding affinity of Drosophila metabotropic glutamate receptor is modulated by association with lipid rafts. Proc Natl Acad Sci U S A 100:10219-10224.

Fernández-Alfonso T, Kwan R, Ryan TA (2006) Synaptic vesicles interchange their membrane proteins with a large surface reservoir during recycling. Neuron 51:179-186.

Gasque G, Labarca P, Darszon A (2005) Cholesterol-depleting compounds modulate $\mathrm{K}^{+}$-currents in Drosophila Kenyon cells. FEBS Lett 579: $5129-5134$

Geumann U, Schäfer C, Riedel D, Jahn R, Rizzoli SO (2010) Synaptic membrane proteins form stable microdomains in early endosomes. Microsc Res Tech 73:606-617.

Grigliatti TA, Hall L, Rosenbluth R, Suzuki DT (1973) Temperaturesensitive mutations in Drosophila melanogaster. XIV. A selection of immobile adults. Mol Gen Genet 120:104-114.

Heerssen H, Fetter RD, Davis GW (2008) Clathrin dependence of synapticvesicle formation at the Drosophila neuromuscular junction. Curr Biol 18:401-409.

Jia JY, Lamer S, Schümann M, Schmidt MR, Krause E, Haucke V (2006) Quantitative proteomics analysis of detergent-resistant membranes from chemical synapses: evidence for cholesterol as spatial organizer of synaptic vesicle cycling. Mol Cell Proteomics 5:2060-2071.

Jouni ZE, McGill B, Wells MA (2002) Beta-cyclodextrin facilitates cholesterol efflux from larval Manduca sexta fat body and midgut in vitro. Comp Biochem Physiol B Biochem Mol Biol 132:699-709.

Karasinska JM, Rinninger F, Lütjohann D, Ruddle P, Franciosi S, Kruit JK, Singaraja RR, Hirsch-Reinshagen V, Fan J, Brunham LR, Bissada N, Ramakrishnan R, Wellington CL, Parks JS, Hayden MR (2009) Specific loss of brain ABCA1 increases brain cholesterol uptake and influences neuronal structure and function. J Neurosci 29:3579-3589.

Karten B, Campenot RB, Vance DE, Vance JE (2006) The Niemann-Pick C1 protein in recycling endosomes of presynaptic nerve terminals. J Lipid Res $47: 504-514$. 
Kasprowicz J, Kuenen S, Miskiewicz K, Habets RL, Smitz L, Verstreken P (2008) Inactivation of clathrin heavy chain inhibits synaptic recycling but allows bulk membrane uptake. J Cell Biol 182:1007-1016.

Kay AR, Alfonso A, Alford S, Cline HT, Holgado AM, Sakmann B, Snitsarev VA, Stricker TP, Takahashi M, Wu LG (1999) Imaging synaptic activity in intact brain and slices with FM1-43 in C. elegans, lamprey, and rat. Neuron 24:809-817.

Koenig JH, Ikeda K (1989) Disappearance and reformation of synaptic vesicle membrane upon transmitter release observed under reversible blockage of membrane retrieval. J Neurosci 9:3844-3860.

Koenig JH, Ikeda K (1996) Synaptic vesicles have two distinct recycling pathways. J Cell Biol 135:797-808.

Koenig JH, Ikeda K (1999) Contribution of active zone subpopulation of vesicles to evoked and spontaneous release. J Neurophysiol 81:1495- 1505.

Lagane B, Gaibelet G, Meilhoc E, Masson JM, Cézanne L, Lopez A (2000) Role of sterols in modulating the human mu-opioid receptor function in Saccharomyces cerevisiae. J Biol Chem 275:33197-33200.

Lang T, Bruns D, Wenzel D, Riedel D, Holroyd P, Thiele C, Jahn R (2001) SNAREs are concentrated in cholesterol-dependent clusters that define docking and fusion sites for exocytosis. EMBO J 20:2202-2213.

Littleton JT (2000) A genomic analysis of membrane trafficking and neurotransmitter release in Drosophila. J Cell Biol 150:F77-F82.

Lloyd TE, Verstreken P, Ostrin EJ, Phillippi A, Lichtarge O, Bellen HJ (2000) A genome-wide search for synaptic vesicle cycle proteins in Drosophila. Neuron 26:45-50.

Lv JH, He L, Sui SF (2008) Lipid rafts association of synaptotagmin I on synaptic vesicles. Biochemistry (Mosc) 73:283-288.

Macleod GT, Hegström-Wojtowicz M, Charlton MP, Atwood HL (2002) Fast calcium signals in Drosophila motor neuron terminals. J Neurophysiol 88:2659-2663.

Macleod GT, Marin L, Charlton MP, Atwood HL (2004) Synaptic vesicles: test for a role in presynaptic calcium regulation. J Neurosci 24:2496-2505.

Martin TF (2000) Racing lipid rafts for synaptic-vesicle formation. Nat Cell Biol 2:E9-E11.

Miesenböck G, De Angelis DA, Rothman JE (1998) Visualizing secretion and synaptic transmission with $\mathrm{pH}$-sensitive green fluorescent proteins. Nature 394:192-195.

Milosevic I, Sørensen JB, Lang T, Krauss M, Nagy G, Haucke V, Jahn R, Neher E (2005) Plasmalemmal phosphatidylinositol-4,5-bisphosphate level regulates the releasable vesicle pool size in chromaffin cells. J Neurosci 25:2557-2565.

Mitchell SJ, Ryan TA (2004) Syntaxin-1A is excluded from recycling synaptic vesicles at nerve terminals. J Neurosci 24:4884-4888.

Mitter D, Reisinger C, Hinz B, Hollmann S, Yelamanchili SV, Treiber-Held S, Ohm TG, Herrmann A, Ahnert-Hilger G (2003) The synaptophysin/ synaptobrevin interaction critically depends on the cholesterol content. J Neurochem 84:35-42.

Phillips SE, Woodruff EA 3rd, Liang P, Patten M, Broadie K (2008) Neuronal loss of Drosophila NPC1a causes cholesterol aggregation and ageprogressive neurodegeneration. J Neurosci 28:6569-6582.

Poskanzer KE, Davis GW (2004) Mobilization and fusion of a non-recycling pool of synaptic vesicles under conditions of endocytic blockade. Neuropharmacology 47:714-723.

Poskanzer KE, Marek KW, Sweeney ST, Davis GW (2003) Synaptotagmin I is necessary for compensatory synaptic vesicle endocytosis in vivo. Nature 426:559-563.

Ramaswami M, Krishnan KS, Kelly RB (1994) Intermediates in synaptic vesicle recycling revealed by optical imaging of Drosophila neuromuscular junctions. Neuron 13:363-375.

Rietveld A, Neutz S, Simons K, Eaton S (1999) Association of sterol- and glycosylphosphatidylinositol-linked proteins with Drosophila raft lipid microdomains. J Biol Chem 274:12049-12054.

Rizzoli SO, Betz WJ (2005) Synaptic vesicle pools. Nat Rev Neurosci 6:57-69.

Rodal SK, Skretting G, Garred O, Vilhardt F, van Deurs B, Sandvig K (1999) Extraction of cholesterol with methyl-beta-cyclodextrin perturbs formation of clathrin-coated endocytic vesicles. Mol Biol Cell 10:961-974.

Romero-Pozuelo J, Dason JS, Atwood HL, Ferrús A (2007) Chronic and acute alterations in the functional levels of Frequenins 1 and 2 reveal their roles in synaptic transmission and axon terminal morphology. Eur J Neurosci 26:2428-2443.

Scanlon SM, Williams DC, Schloss P (2001) Membrane cholesterol modulates serotonin transporter activity. Biochemistry 40:10507-10513.
Shmygol A, Noble K, Wray S (2007) Depletion of membrane cholesterol eliminates the $\mathrm{Ca}^{2+}$-activated component of outward potassium current and decreases membrane capacitance in rat uterine myocytes. J Physiol 581:445-456.

Shreve SM, Yi SX, Lee RE Jr (2007) Increased dietary cholesterol enhances cold tolerance in Drosophila melanogaster. Cryo Letters 28:33-37.

Smith AJ, Sugita S, Charlton MP (2010) Cholesterol-dependent kinase activity regulates transmitter release from cerebellar synapses. J Neurosci 30:6116-6121.

Subtil A, Gaidarov I, Kobylarz K, Lampson MA, Keen JH, McGraw TE (1999) Acute cholesterol depletion inhibits clathrin-coated pit budding. Proc Natl Acad Sci U S A 96:6775-6780.

Suzuki S, Numakawa T, Shimazu K, Koshimizu H, Hara T, Hatanaka H, Mei L, Lu B, Kojima M (2004) BDNF-induced recruitment of TrkB receptor into neuronal lipid rafts: roles in synaptic modulation. J Cell Biol 167:1205-1215

Takamori S, Holt M, Stenius K, Lemke EA, Grønborg M, Riedel D, Urlaub H, Schenck S, Brügger B, Ringler P, Müller SA, Rammner B, Gräter F, Hub JS, De Groot BL, Mieskes G, Moriyama Y, Klingauf J, Grubmüller H, Heuser J, et al. (2006) Molecular anatomy of a trafficking organelle. Cell 127:831-846.

Taverna E, Saba E, Rowe J, Francolini M, Clementi F, Rosa P (2004) Role of lipid microdomains in P/Q-type calcium channel (Cav2.1) clustering and function in presynaptic membranes. J Biol Chem 279:5127-5134.

Thiele C, Hannah MJ, Fahrenholz F, Huttner WB (2000) Cholesterol binds to synaptophysin and is required for biogenesis of synaptic vesicles. Nat Cell Biol 2:42-49.

Toselli M, Biella G, Taglietti V, Cazzaniga E, Parenti M (2005) Caveolin-1 expression and membrane cholesterol content modulate $\mathrm{N}$-type calcium channel activity in NG108-15 cells. Biophys J 89:2443-2457.

Urs NM, Jones KT, Salo PD, Severin JE, Trejo J, Radhakrishna H (2005) A requirement for membrane cholesterol in the beta-arrestin- and clathrindependent endocytosis of LPA1 lysophosphatidic acid receptors. J Cell Sci 118:5291-5304.

Verstreken P, Ohyama T, Bellen HJ (2008) FM 1-43 labeling of synaptic vesicle pools at the Drosophila neuromuscular junction. Methods Mol Biol 440:349-369.

Wang R, Hosaka M, Han L, Yokota-Hashimoto H, Suda M, Mitsushima D, Torii S, Takeuchi T (2006) Molecular probes for sensing the cholesterol composition of subcellular organelle membranes. Biochim Biophys Acta 1761:1169-1181.

Wasser CR, Ertunc M, Liu X, Kavalali ET (2007) Cholesterol-dependent balance between evoked and spontaneous synaptic vesicle recycling. J Physiol 579:413-429.

Wienisch M, Klingauf J (2006) Vesicular proteins exocytosed and subsequently retrieved by compensatory endocytosis are nonidentical. Nat Neurosci 9:1019-1027.

Willig KI, Rizzoli SO, Westphal V, Jahn R, Hell SW (2006) STED microscopy reveals that synaptotagmin remains clustered after synaptic vesicle exocytosis. Nature 440:935-939.

Wu LG, Ryan TA, Lagnado L (2007) Modes of vesicle retrieval at ribbon synapses, calyx-type synapses, and small central synapses. J Neurosci 27:11793-11802.

Yancey PG, Bielicki JK, Johnson WJ, Lund-Katz S, Palgunachari MN, Anantharamaiah GM, Segrest JP, Phillips MC, Rothblat GH (1995) Efflux of cellular cholesterol and phospholipid to lipid-free apolipoproteins and class A amphipathic peptides. Biochemistry 34:7955-7965.

Yoshinaka K, Kumanogoh H, Nakamura S, Maekawa S (2004) Identification of V-ATPase as a major component in the raft fraction prepared from the synaptic plasma membrane and the synaptic vesicle of rat brain. Neurosci Lett 363:168-172.

Zamir O, Charlton MP (2006) Cholesterol and synaptic transmitter release at crayfish neuromuscular junctions. J Physiol 571:83-99.

Zenisek D, Steyer JA, Feldman ME, Almers W (2002) A membrane marker leaves synaptic vesicles in milliseconds after exocytosis in retinal bipolar cells. Neuron 35:1085-1097.

Zhuang M, Oltean DI, Gómez I, Pullikuth AK, Soberón M, Bravo A, Gill SS (2002) Heliothis virescens and Manduca sexta lipid rafts are involved in CrylA toxin binding to the midgut epithelium and subsequent pore formation. J Biol Chem 277:13863-13872. 